\title{
RADIATION AND CHEMICAL REACTION EFFECTS ON MHD CASSON FLUID FLOW OF A POROUS MEDIUM WITH SUCTION/INJECTION
}

\author{
Nagaraju Vellanki \\ Research scholar, Department of Mathematics, \\ Krishna University, Machilipatnam, A.P, India.
}

Dr. K. Hemalatha

Department of Mathematics, V. R. Siddhartha Engineering college, Vijayawada, A.P, India.

\section{Dr. G. Venkata Ramana Reddy}

Department of Mathematics, KL University, Vaddeswaram, Vijayawada, A.P, India.

\begin{abstract}
This research article explores on the steady of the two-dimensional buoyancy effects on MHD Casson fluid flow over a stretching of permeable sheet through a porous medium in the occurrence of suction/injection. The central PDEs are changed into ODEs by applying similarity transformations and the changed equations' solutions are got by Runge-Kutta fourth order along with a shooting technique. The working fluid flow is considered for numerous different parameters graphically. It has been observed that velocity decreases, temperature and concentration increase when magnetic field and permeability of porous parameter increases.
\end{abstract}

Keywords: MHD, Chemical reaction, Porous medium, Buoyancy effects, Stretching sheet, Suction/injection.

Cite this Article: Nagaraju Vellanki, Dr. K. Hemalatha and Dr. G. Venkata Ramana Reddy, Radiation and Chemical Reaction Effects on MHD Casson Fluid Flow of a Porous Medium with Suction/Injection, International Journal of Mechanical Engineering and Technology 11(2), 2020, pp. 99-116.

https://iaeme.com/Home/issue/IJMET?Volume=11\&Issue=2

\section{INTRODUCTION}

Owing to the badly need for good understanding of associate transfer phenomena heat transfer through a porous medium has become an interesting subject for last three decades. There is large number of practical applications in modelling transport through porous media in literature insensible heat storage beds and beds of fossil fuels such as oil shale and coal, salt leaching in soils, packed sphere beds, chemical, high performance insulation for buildings, chemical catalytic reactors, mechanical, environmental, grain storage, migration of moisture through their contained in fibrous insulations, geological, heat exchange between soil and atmosphere, 
solar power collectors, electrochemical processes, insulation of nuclear reactors, regenerative heat exchangers and geothermal energy systems, petroleum and many other areas.

Kuznetsov et.al [1] has examined the normal convection limit layer stream of a nanofluid past a vertical plate. Nabil et.al [2] examined in his paper on MHD stream of non-Newtonian visco-versatile liquid through a permeable medium close to a quickened plate. Nabil et.al [3] represents Non-Darcy couette course through a permeable mode of MHD visco-flexible liquid with warmth and mass exchange. M. Hameedet.al [4] contemplated Unsteady MHD stream of a non-Newtonian liquid on a permeable plate. Rajesh [5] broke down MHD impacts on free convection and mass change course through a permeable medium with variable temperatures. Sengupta [6] studied Thermal dispersion impact of free convection mass exchange stream past a consistently quickened permeable plate with warmth sink. Bhattacharya [7] talked about impacts of warmth source/sink on MHD stream and warmth move over a contracting sheet with mass suction. Turkyilmazogluet.al [8] have examined Soret and warmth source impacts on an insecure radiative MHD free convection stream from a rashly begun endless vertical plate. Narahari [9] contemplated a precise arrangement of precarious MHD free convection stream of an emanating gas past an interminable slanted isothermal plate.

Nadeem et.al [10] has displayed MHD three-dimensional Casson liquid stream past a permeable straightly extending sheet. Haqet.al [11] has contemplated convective warmth move and MHD impacts on Casson nanofluid stream over a contracting sheet. Kameswaraniet.al [12] broke down double arrangements of Casson liquid stream over an extending or contracting sheet. Babuet.al [13] talked about radiation impact on MHD warmth and mass exchange stream over a contracting sheet with mass suction.

Kirubhashankar et.al [14] examined Casson liquid stream and warmth move over a shaky permeable extending surface. Maboodet.al [15] has contemplated MHD limit layer stream and warmth move of nanofluids over a nonlinear extending sheet. Kataria et.al [16] examined radiation and synthetic response consequences for MHD Casson liquid stream past a swaying vertical plate implanted in permeable medium. Raju et.al [17] additionally examined warmth and mass exchange in magnetohydrodynamic Casson liquid over an exponentially penetrable extending surface. Mabood et.al [18] displayed impacts of Soret and non-uniform warmth source on MHD non-Darcian convective stream over an extending sheet in a dissipative micropolar liquid with radiation.

Yasin et.al [19] examined MHD warmth and mass exchange stream over a porous extending/contracting sheet with radiation impact. Bhattiet.al [20] examined head-on impact between two hydroelastic single waves in shallow water. Katariaet.al [21] examined warmth and mass exchange in MHD Casson liquid stream past over a wavering vertical plate implanted in permeable medium with inclined divider temperature. In this warmth and mass exchange numerous creators [22]-[26] talked about.

\section{MATHEMATICAL FORMULATION}

Let us take a steady 2D, electrically conducting non-Newtonian Casson fluid flow of a viscous and incompressible over a permeable stretching sheet is considered. The stretching sheet's velocity is taken in the form $\lambda\left[u_{\omega}(x)\right]$ with $\lambda \in(0, \infty)$ for a stretching surface. Here horizontal and vertical axes are taken on the stretching surface and the normal to it, respectively. Beside the flow is being confined to $\lambda \in(0, \infty)$. It is considered that the surface is permeable and the mass flux velocity $v_{0}$. For suction and injection $v_{0}$ is negative and positive respectively. 
The rheological properties of Casson fluid for an isotropic and incompressible flow is given by Eldabe et al [27] and Mustafa et al [28].

$$
\tau_{i j}= \begin{cases}2\left(\mu_{B}+p_{y} / \sqrt{2 \pi}\right) e_{i j}, & \pi>\pi_{c} \\ 2\left(\mu_{B}+p_{y} / \sqrt{2 \pi_{c}}\right) e_{i j}, & \pi<\pi_{c}\end{cases}
$$

where $\mu_{B}$ is the plastic dynamic viscosity of the non-Newtonian fluid, $p_{y}$ is the yield stress of the fluid , $\pi$ - the product of the component of deformation rate with itself, $\pi=e_{i j} e_{i j}, e_{i j}$ is the $(i, j)^{\text {th }}$ component of the deformation rate, and $\pi_{c}$ - the critical value of $\pi$ based on nonNewtonian model.

The following are taken into consideration:

$T_{w}=$ constant temperature at surface of the sheet

$C_{w}=$ concentration at the surface of the sheet

$T_{\infty}=$ constant temperature of ambient fluid

$C_{\infty}$. =concentration of ambient fluid

Yasin et al. [19] in their research article proposed the system of equations which model the flow as:

$$
\begin{gathered}
u_{x}+u_{y}=0 \\
u u_{x}+v u_{y}=v\left(1+\frac{1}{\beta}\right) u_{y y}-\left(\frac{\sigma B_{0}^{2}}{\rho}+\frac{v}{k^{\prime}}\right) u+g \beta_{T}\left(T-T_{\infty}\right)+g \beta_{C}\left(C-C_{\infty}\right) \\
\rho C_{p}\left(u T_{x}+v T_{y}\right)=\alpha\left(\rho C_{p}\right) T_{y y}-q_{r y}+Q_{0}\left(T-T_{\infty}\right) \\
u C_{x}+v C_{y}=D_{B} C_{y y}-k_{0}\left(C-C_{\infty}\right)
\end{gathered}
$$

Here $\mathrm{u}=$ velocity component in $x$ - axes direction

$\mathrm{v}=$ the velocity component in $y$-axes direction,

$T=$ the fluid temperature,

$C=$ the concentration,

$v=$ kinematic viscosity of the fluid,

$\alpha=$ thermal diffusivity of the fluid,

$\rho=$ the density of the fluid,

$D_{B}=$ Brownian diffusion coefficient,

$C_{p}=$ specific heat at constant pressure,

$\sigma=$ electric conductivity of the fluid,

$B_{0}=$ applied uniform magnetic field normal to the surface of the sheet, 
Radiation and Chemical Reaction Effects on MHD Casson Fluid Flow of a Porous Medium with Suction/Injection

$$
q_{r}=\left\{\begin{array}{l}
\text { heat source if } \mathrm{Q}_{0}>0 \\
\text { heat sink if } \mathrm{Q}_{0}<0
\end{array}\right.
$$

$\mathrm{g}=$ acceleration due to gravity

$\beta_{T}=$ the coefficient of thermal expansion,

$\beta_{C}=$ the coefficient of solutal expansion

$k^{\prime}=$ porous medium permeability coefficient

and $k_{0}=$ the constant chemical reaction rate.

We consider that constrains (1)-(4) are subjected to the boundary conditions:

$$
\begin{array}{ll}
v=v_{0}, u=\lambda u_{w}(x), T=T_{w}, C=C_{w}, & \text { at } y=0 \\
u \rightarrow 0, T \rightarrow T_{\infty} C \rightarrow C_{\infty} & \text { as } y \rightarrow \infty
\end{array}
$$

where we assume that $u_{w}(x)=a x$, with $a>0$.

The energy Equation (3) is expressed as (by applying Rosseland approximation (Brewster, 1992) and Suneetha et al. [22]):

$$
u T_{x}+v T_{y}=\alpha\left(1+\left(3 k k^{*}\right)^{-1} 16 \sigma^{*} T_{\infty}^{3}\right) T_{y y}-Q^{0}\left(\rho C_{p}\right)^{-1}\left(T_{\infty}-T\right)
$$

here $k=$ thermal conductivity, $\sigma^{*}=$ Stefan-Boltzmann constant and $k^{*}=$ mean absorption coefficient.

The similarity solution of (1), (2), (4) and (6) are obtained as:

$$
\psi=(a v)^{1 / 2} x f(\eta), \theta(\eta)=\frac{\left(T_{\infty}-T\right)}{\left(T_{\infty}-T_{w}\right)}, \phi(\eta)=\frac{\left(C_{\infty}-C\right)}{\left(C_{\infty}-C_{w}\right)}, \eta=y(a / v)^{1 / 2}
$$

Here $\psi(x, y)=$ stream function, which is defined in the usual way as $u=\partial \Psi / \partial y$, and $v=-\partial \psi / \partial x$. Thus, we have:

$$
u=a x f^{\prime}(\eta), v=-(a v)^{1 / 2} f(\eta)
$$

Hence the parameter $\mathrm{S}$ having no dimension is described by:

$$
S=-v_{0}(a v)^{-1 / 2}
$$

$S$ is the constant mass flux with $S=\left\{\begin{array}{l}\text { positive, for suction } \\ \text { negative, for injection }\end{array}\right.$

The following ODEs are got by putting (7) in (2), (6) and (4)

$$
\begin{gathered}
(1+\beta) f^{\prime \prime \prime}+\beta\left(f f^{\prime \prime}-f^{\prime 2}-(M+K) f^{\prime}+G r \theta+G c \phi\right)=0 \\
\left(\frac{3+4 R}{3 \operatorname{Pr}}\right) \theta^{\prime \prime}+f \theta^{\prime}+Q \theta=0 \\
\phi^{\prime \prime}+S c f \phi^{\prime}-S c K r \phi=0 .
\end{gathered}
$$


The corresponding boundary conditions:

$$
\begin{aligned}
& f(\eta)=S, f^{\prime}(\eta)=\lambda, \theta(\eta)=1, \phi(\eta)=1 \quad \text { at } \eta=0 \\
& f^{\prime}(\eta) \rightarrow 0, \theta(\eta) \rightarrow 0, \phi(\eta) \rightarrow 0 \quad \text { as } \eta \rightarrow \infty
\end{aligned}
$$

The constants $\operatorname{Pr}, S c, M, R, G r, G c, Q, K$ and $\mathrm{Kr}$ are not possessing any dimension and their description are given below

\begin{tabular}{|c|c|}
\hline Constants & Description \\
\hline $\mathrm{Pr}$ & Prandtl number \\
\hline $\mathrm{Sc}$ & Schmidt number \\
\hline $\mathrm{M}$ & Magnetic parameter \\
\hline $\mathrm{R}$ & Radiation parameter \\
\hline $\mathrm{Gr}$ & Thermal Grashof number \\
\hline $\mathrm{Gc}$ & Solutal Grashof number \\
\hline $\mathrm{Q}$ & Heat source/sink parameter \\
\hline $\mathrm{K}$ & Permeability parameter \\
\hline $\mathrm{Kr}$ & Chemical reaction parameter \\
\hline
\end{tabular}

$\operatorname{Pr}=v \alpha^{-1}, S c=v D_{B}^{-1}, M=\sigma B_{0}^{2} \rho^{-1}, R=\left(k k^{*}\right)^{-1} 4 \sigma^{*} T_{\infty}^{3}$,

$G r=\left(a^{2} x\right)^{-1} g \beta_{T}\left(T_{w}-T_{\infty}\right), G c=\left(a^{2} x\right)^{-1} g \beta_{c}\left(C_{w}-C_{\infty}\right), Q=\left(a \rho C_{p}\right)^{-1} Q_{0}$,

$K=\left(k^{\prime} a\right)^{-1} v, K r=a^{-1} k_{0}, S r=\frac{D_{T}}{v}\left(\frac{T_{\infty}-T_{w}}{C_{\infty}-C_{w}}\right)$

The most important quantities in the above phenomenon are given by

$C_{f}=$ skin friction coefficient,

$N u_{x}=$ local Nusselt number

$S h_{x}=$ local Sherwood number,

$$
C_{f}=\tau_{w} / \rho u_{w}^{2}(x), N u_{x}=x q_{w} / k\left(T_{w}-T_{\infty}\right), S h_{x}=x q_{m} / D_{B}\left(C_{w}-C_{\infty}\right)
$$

here $\tau_{w}=$ skin friction or shear stress,$q_{w}=$ heat flux and $q_{m}=$ mass flux from the sheet, which are given by:

$$
\tau_{w}=\mu\left(\frac{\partial u}{\partial y}\right)_{y=0}, q_{w}=-\left(\frac{\partial T}{\partial y}\right)_{y=0}+\left(q_{r}\right)_{y=0}, q_{m}=-D_{B}\left(\frac{\partial C}{\partial y}\right)_{y=0},
$$

here $\mu$ =fluid's dynamic viscosity.

By (7), (15) and (16), one can get:

$$
\sqrt{\operatorname{Re}_{x}} C_{f}=f^{\prime \prime}(0), \frac{N u_{x}}{\sqrt{\operatorname{Re}_{x}}}=-\left(\frac{3+4 R}{3}\right) \theta^{\prime}(0), \frac{S h_{x}}{\sqrt{\operatorname{Re}_{x}}}=-\phi^{\prime}(0),
$$

Where $\operatorname{Re}_{x}=u_{w}(x) x / v$ is the local Reynolds number. 


\section{RESULTS AND DISCUSSION}

The similarity transformation changes the non-linear PDEs (2)-(4) into ODEs. The set of nonlinear ODEs (10)-(12) with boundary conditions in (13) can be solved numerically using $4^{\text {th }}$ order Runge-Kutta method along with shooting method and the corresponding MATLAB software is provided.

Figure (2)- (4) speak to the velocity, temperature and focus profiles for various estimations of attractive parameter. It is seen that an augmentation of an attractive parameter gets an improvement Lorentz power so velocity profiles diminishes with increment in attractive parameter. It is additionally seen that the temperature and fixation increment as the attractive parameter increment in both the instances of suction and infusion fundamentally after certain separation ordinary to the sheet. Figure (5)- (7) portray the velocity, temperature and fixation profiles for various estimations of Permeability parameter $(\mathrm{K})$. It is seen that the velocity diminishes with expanding $\mathrm{K}$ and it is likewise seen that the temperature and focus profiles increment with expanding estimations of $\mathrm{K}$ for both the instance of suction and infusion separately. Physical parts of velocity, temperature and focus profiles are thought with the guide of figures (8), (9) and (10) individually. It is seen that the velocity profiles increment with an expansion in Grashof number (Gr) due to $\mathrm{Gr}$ impact of warm lightness power to the gooey hydrodynamic power in the limit layer thickness. Here Gr expands the temperature and focus decline for both the instances of suction and infusion parameter.

The effect of the changed Grashof number $(\mathrm{Gm})$ on the velocity, temperature and fixation profiles are appeared in figures (11)- (13). It was discovered that the expansion in the Gm expands the velocity. Be that as it may, turn around pattern is seen in the temperature and fixation profiles for the instances of suction and infusion. Figures (14) and (15) demonstrate the varieties in velocity and temperature profile separately. It is seen that the velocity and temperature fields are expanding for rising estimations of the warm radiation because of this expansion the limit layer broadness in both the instances of suction and infusion. Impact of Prandtl number $(\operatorname{Pr})$ on the velocity, temperature and focus profile are exhibited in figures (16),(17) and (18) individually. It is seen that the velocity is diminished with expanding Prandtl number. Physically, it is genuine in light of the fact that an addition in the Pr is because of an expansion in the consistency of the liquid, which makes the liquid thick and subsequently it diminishes in the liquid of the velocity both the instances of suction and infusion. It is seen that the temperature just as the warm limit layer thickness decline because of the expansion of Pr. The switched pattern is seen on the focus field both the cases suction and infusion.

Impacts of warmth source parameter on the velocity, temperature and fixation profiles are appeared in figures (19), (20) and (21) separately. It is seen that as warmth source parameter increment, velocity and temperature increment. However, turn around pattern is seen in the focus profiles for both the instances of suction and infusion. Impact of the Schmidt number (Sc) on the velocity, temperature and focus profiles are appeared in the figures (22), (23) and (24) separately. It tends to be reason that the velocity and fixation profiles decline with the expansion in Schmidt number and furthermore it is seen that temperature increments with the expansion in Sc. Figures (25), (26) and (27) speak to the velocity, temperature and focus profiles for various estimations of concoction response parameter. It is seen that the velocity and fixation profiles decline with the expansion in concoction response parameter. It is additionally seen that the temperature field increments with the expansion in substance response parameter. Figs (28), (29),(30) shows the impact of Casson liquid parameter( $\beta$ ) on the velocity, mild and focus profiles. It was discovered that the Casson liquid parameter expands the liquid thickness builds this causes the reductions the liquid velocity yet switch pattern saw in the temperature and focus 
profiles increments when expanding the Casson liquid parameter because of warm and mass diffusivity.

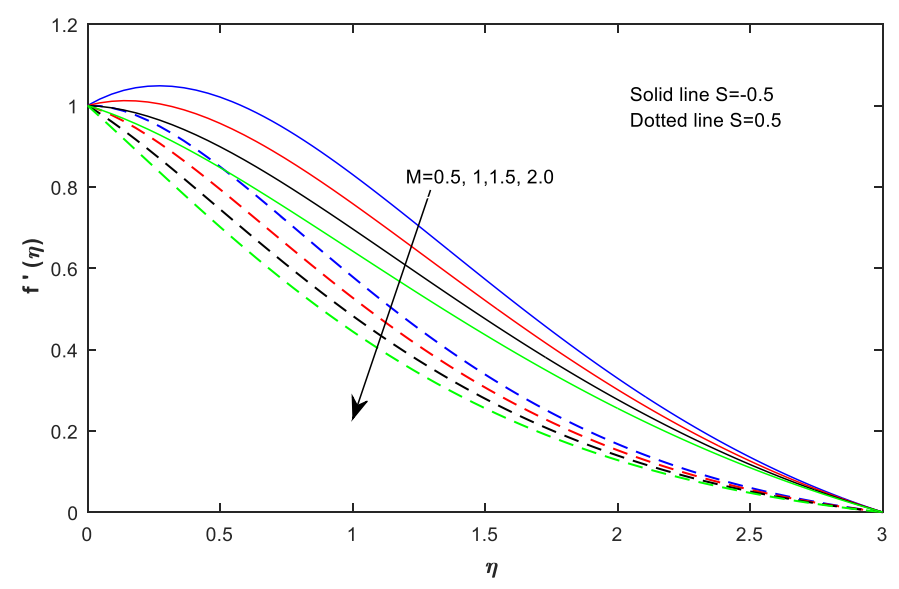

Figure 2 Velocity profiles for different values of Magnetic Parameter (M)

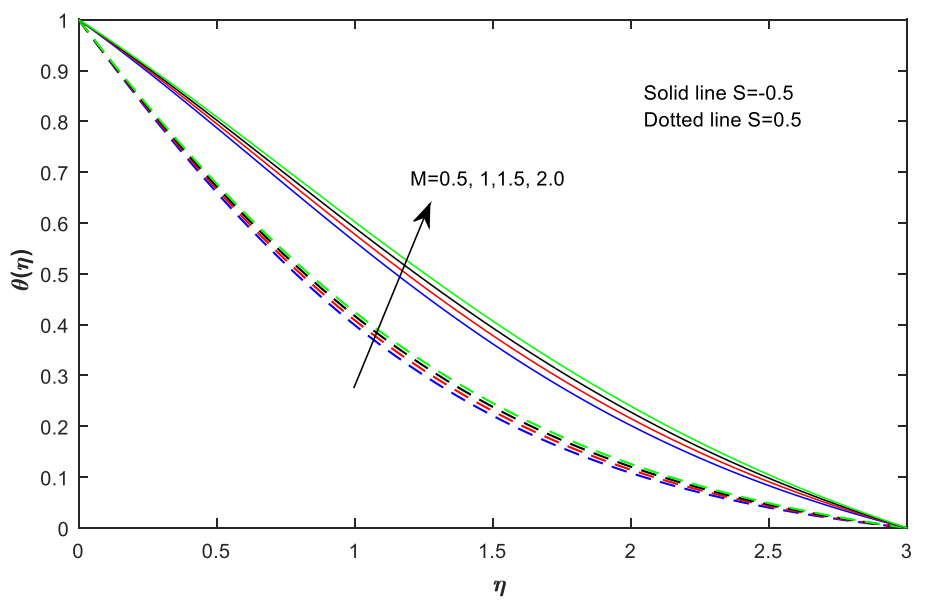

Figure 3 Temperature profiles for different values of Magnetic Parameter (M)

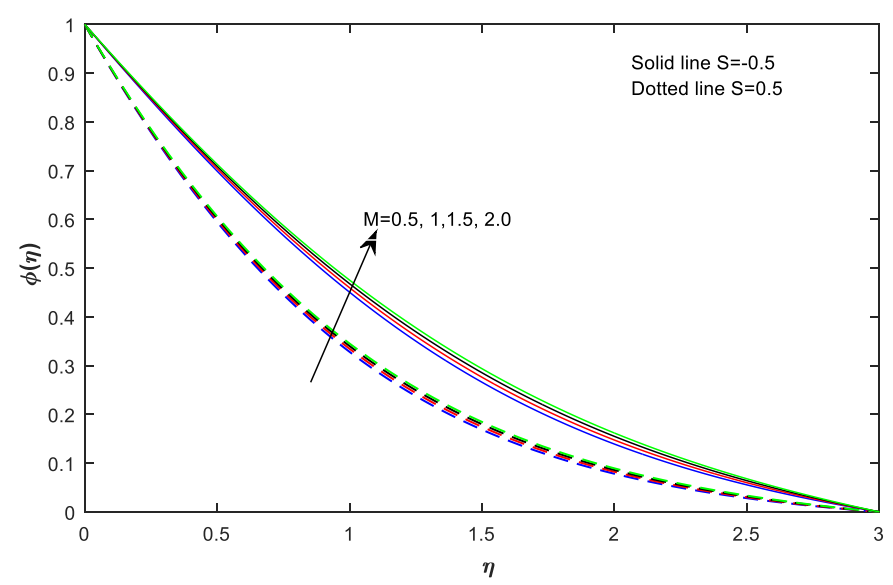

Figure 4 Concentration profiles for different values of Magnetic Parameter (M) 
Radiation and Chemical Reaction Effects on MHD Casson Fluid Flow of a Porous Medium with Suction/Injection

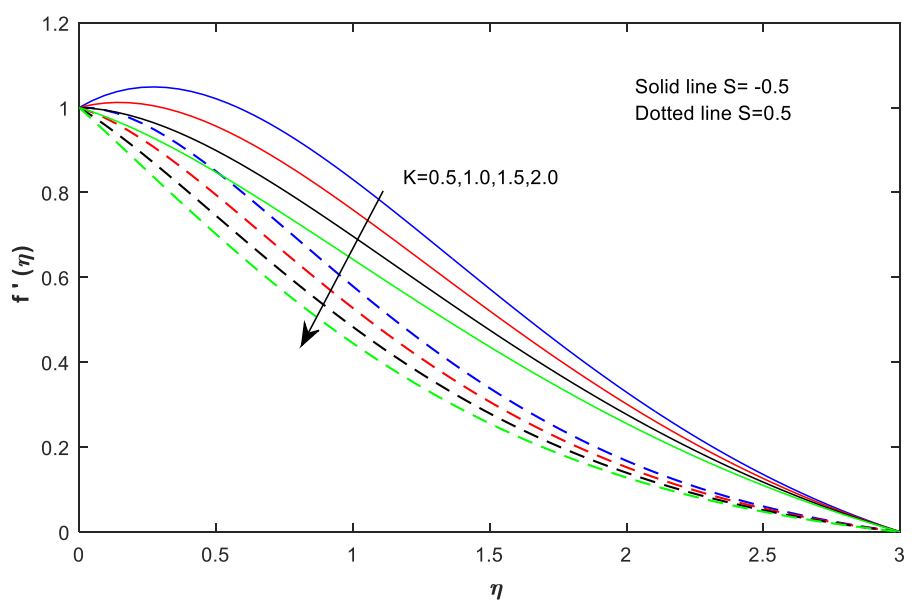

Figure 5 Velocity profiles for different values of Permeability parameter (K)

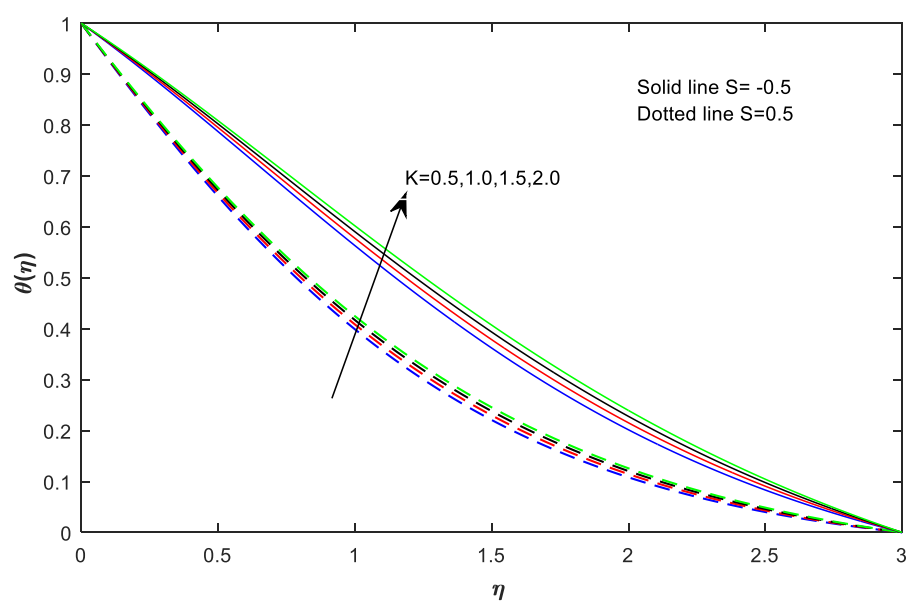

Figure 6 Temperature profiles for different values of Permeability parameter (K)

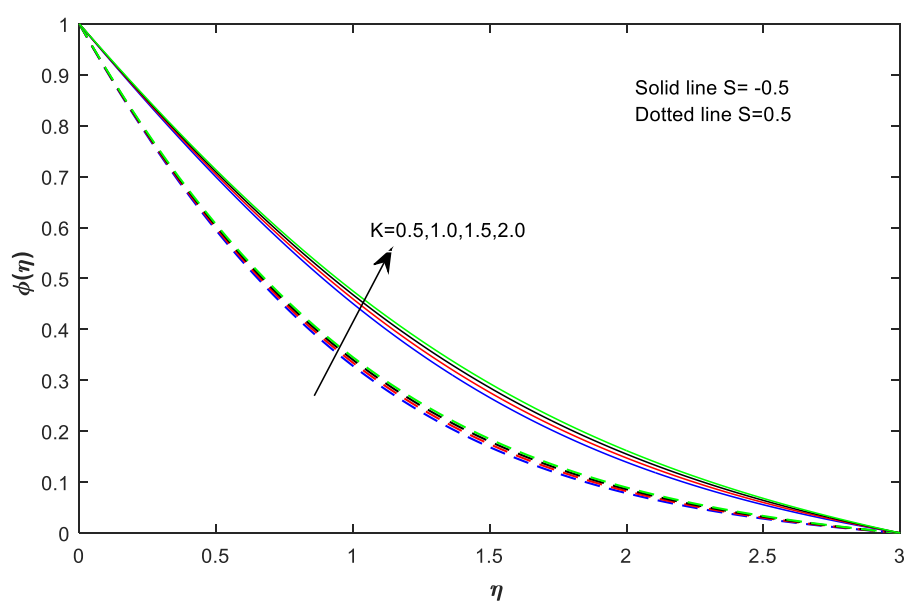

Figure 7 Concentration profiles for different values of Permeability parameter (K) 
Nagaraju Vellanki, Dr. K. Hemalatha and Dr. G. Venkata Ramana Reddy

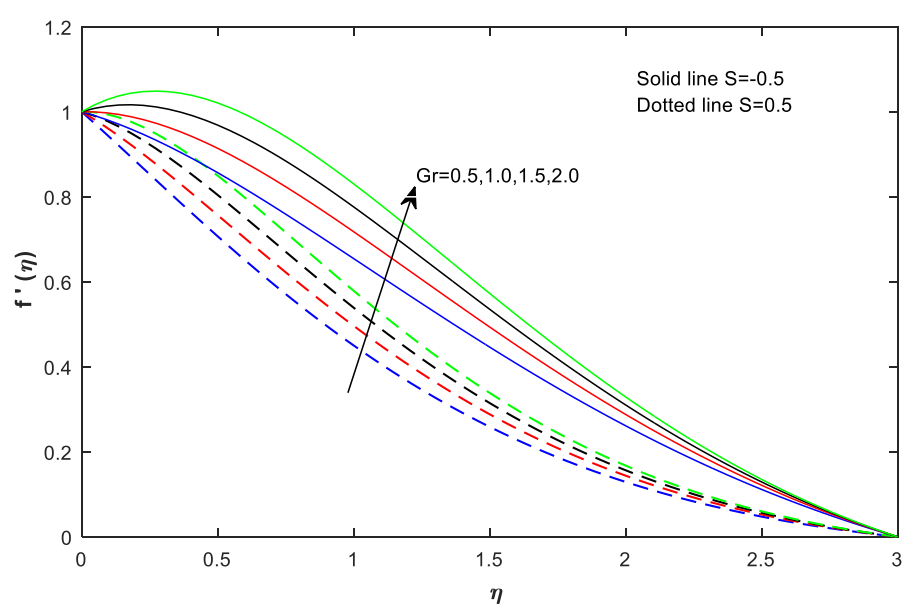

Figure 8 Velocity profiles for different values of Grashoff number (Gr)

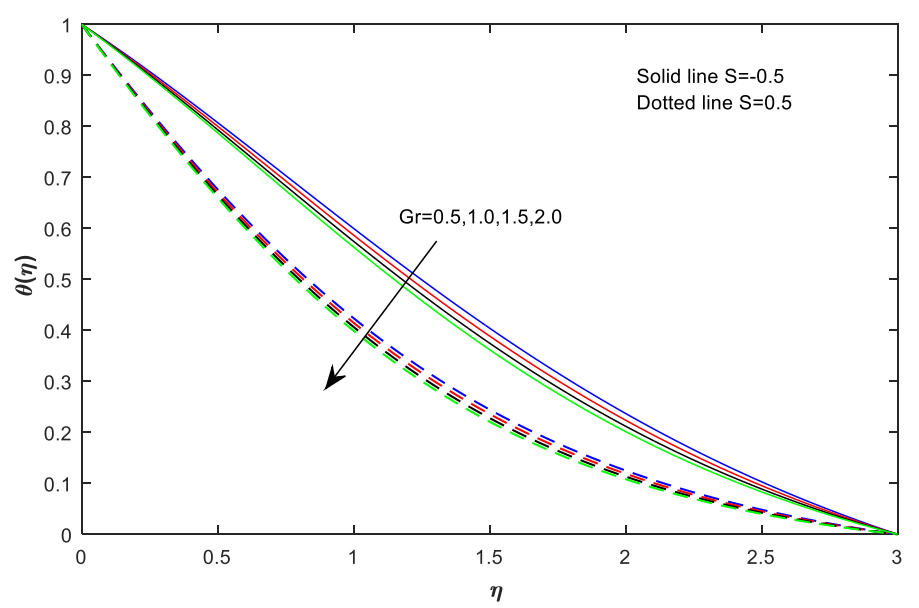

Figure 9 Temperature profiles for different values of Grashoff number (Gr)

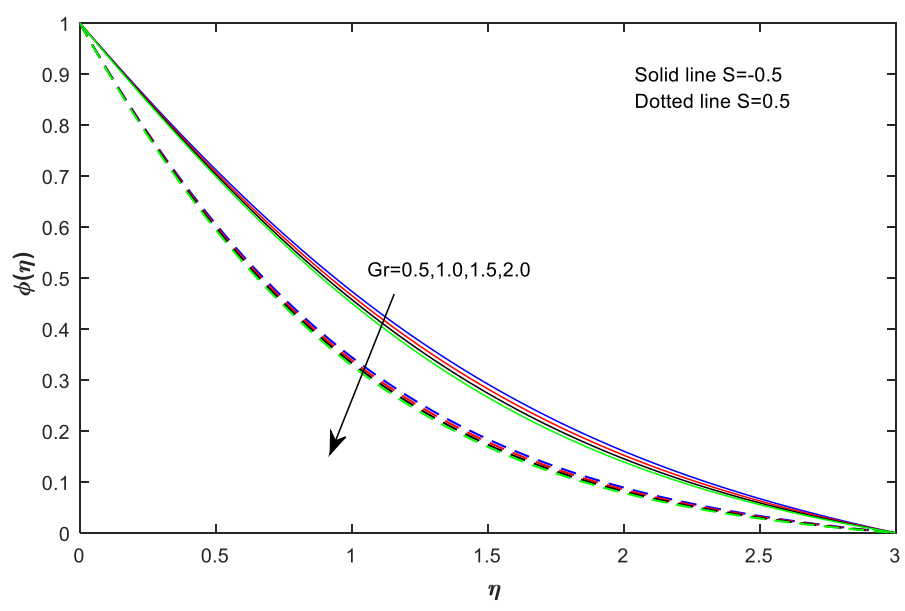

Figure 10 Concentration profiles for different values of Grashoff number $(\mathrm{Gr})$ 
Radiation and Chemical Reaction Effects on MHD Casson Fluid Flow of a Porous Medium with Suction/Injection

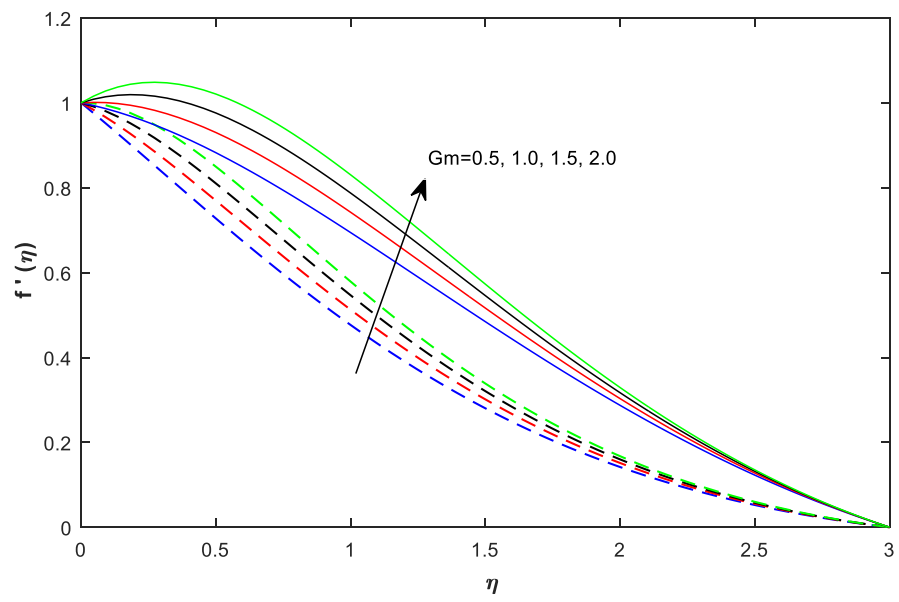

Figure 11 Velocity profiles for different values of modified Grashoff number (Gm)

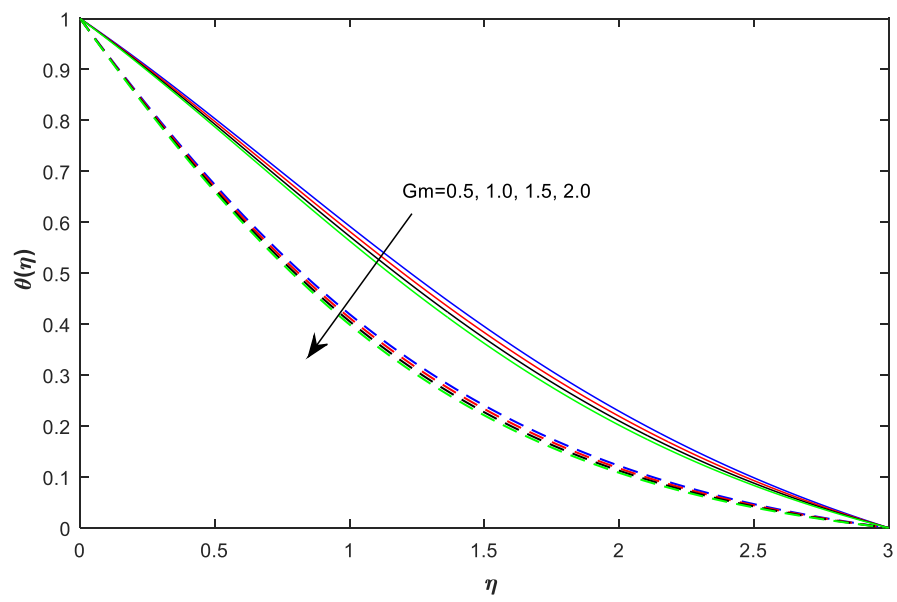

Figure 12 Temperature profiles for different values of modified Grashoff number $(\mathrm{Gm})$

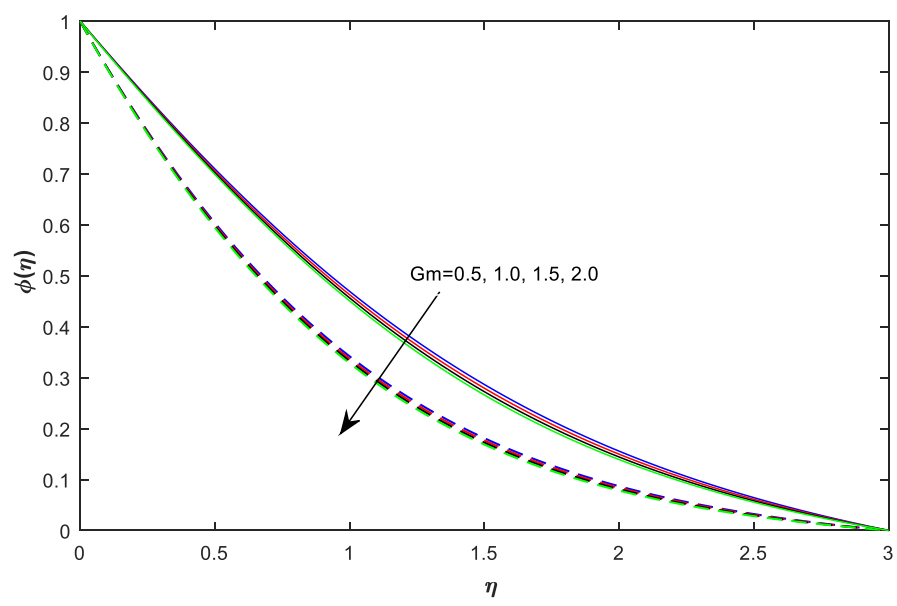

Figure 13 Concentration profiles for different values of modified Grashoff number $(\mathrm{Gm})$ 
Nagaraju Vellanki, Dr. K. Hemalatha and Dr. G. Venkata Ramana Reddy

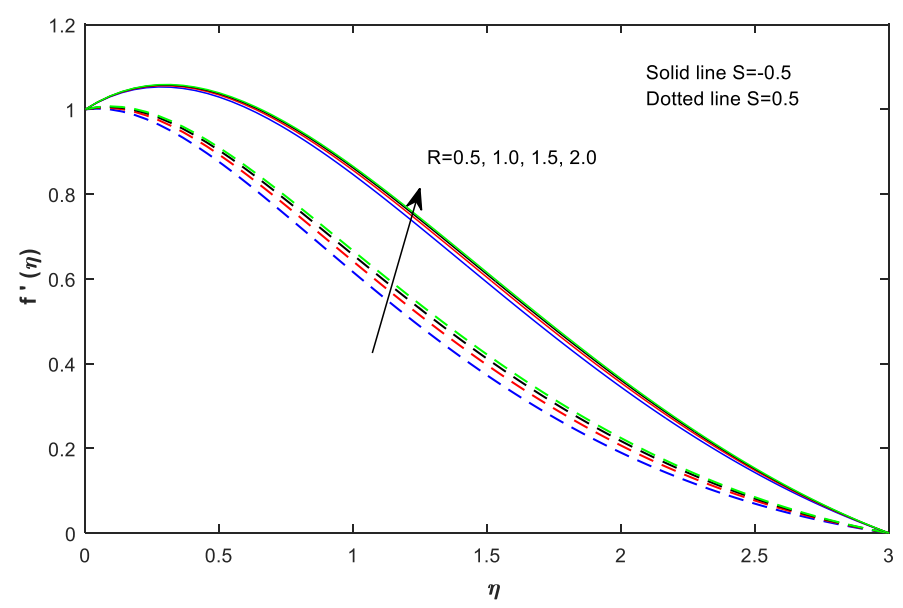

Figure 14 Velocity profiles for different values of radiation parameter (R)

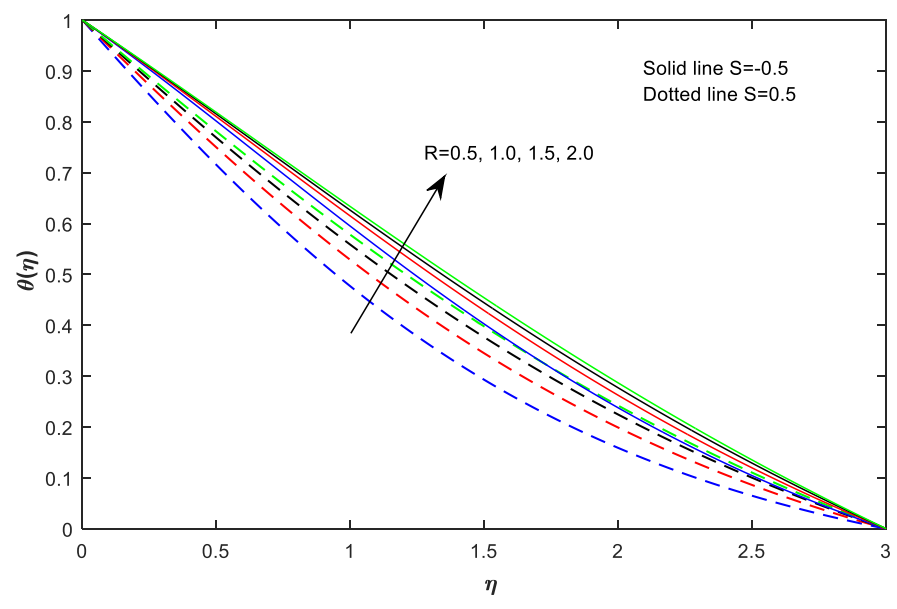

Figure 15 Temperature profiles for different values of radiation parameter (R)

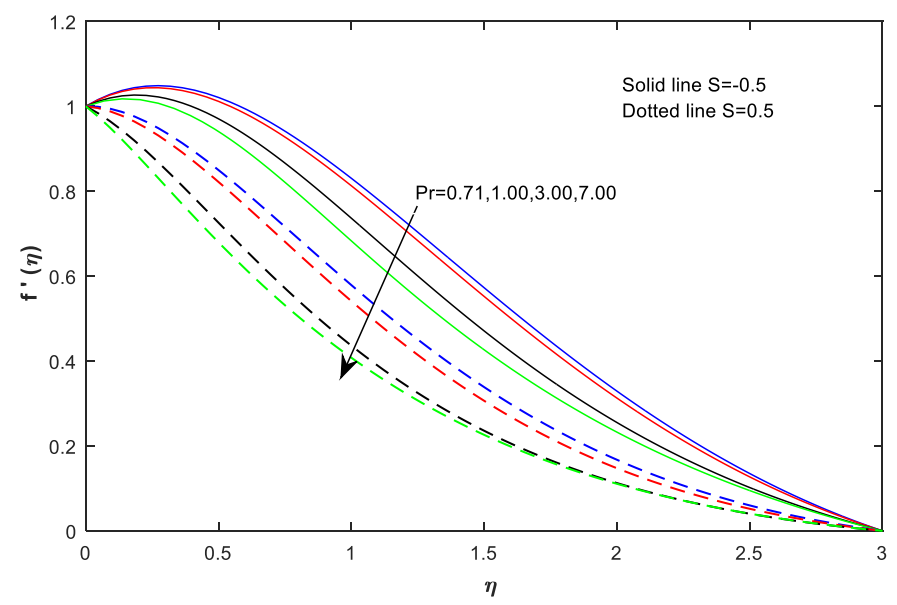

Figure 16 Velocity profiles for different values of Prandtl number (Pr) 
Radiation and Chemical Reaction Effects on MHD Casson Fluid Flow of a Porous Medium with Suction/Injection

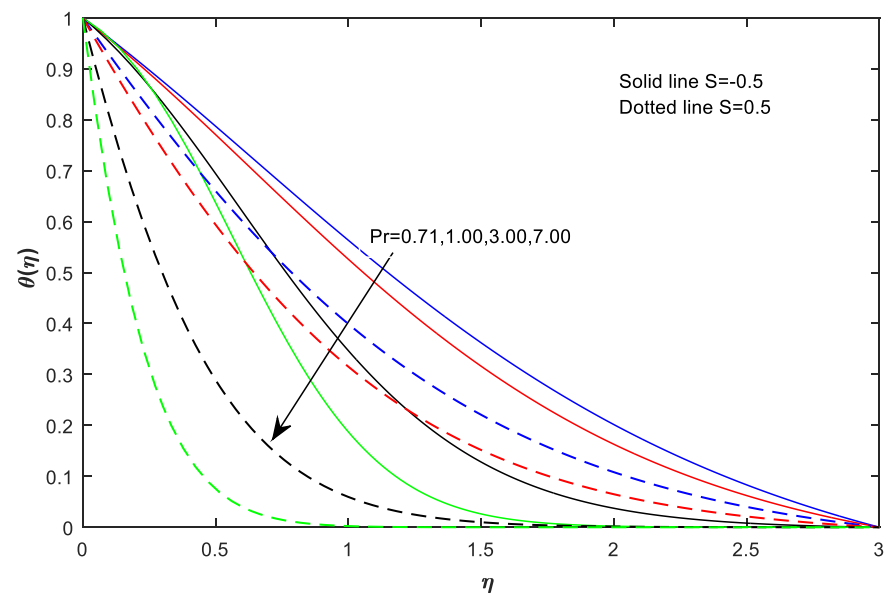

Figure 17 Temperature profiles for different values of Prandtl number(Pr)

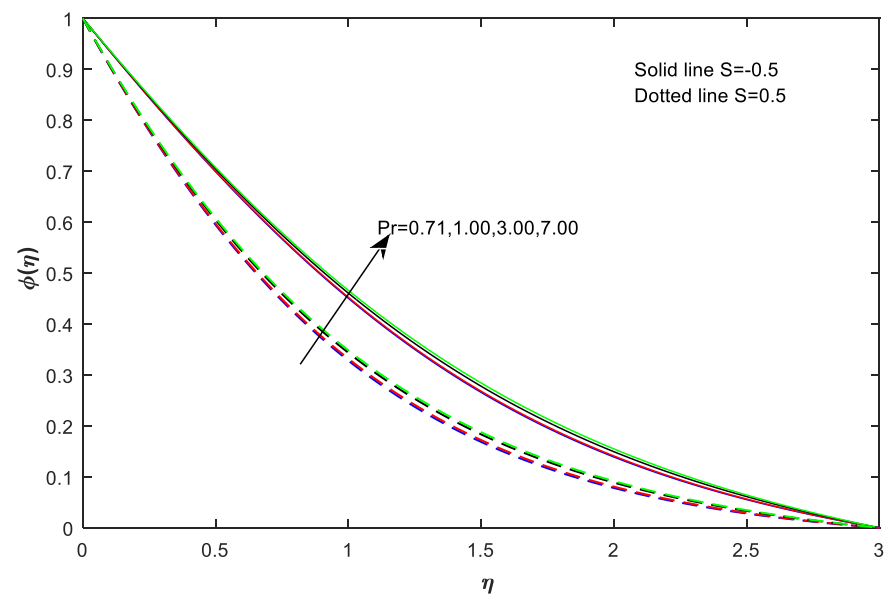

Figure 18 Concentration profiles for different values of Prandtl number(Pr)

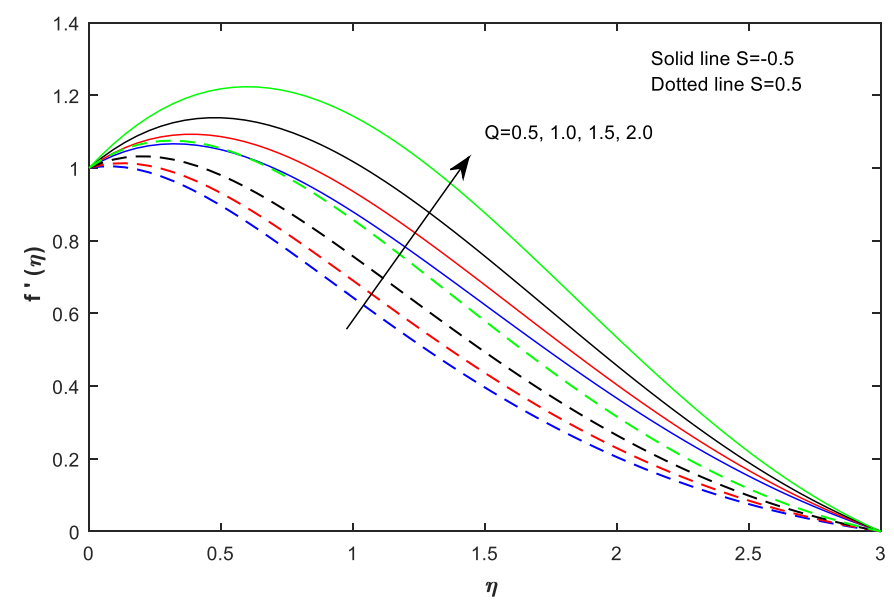

Figure 19 Velocity profiles for different values ofheat source parameter(Q) 


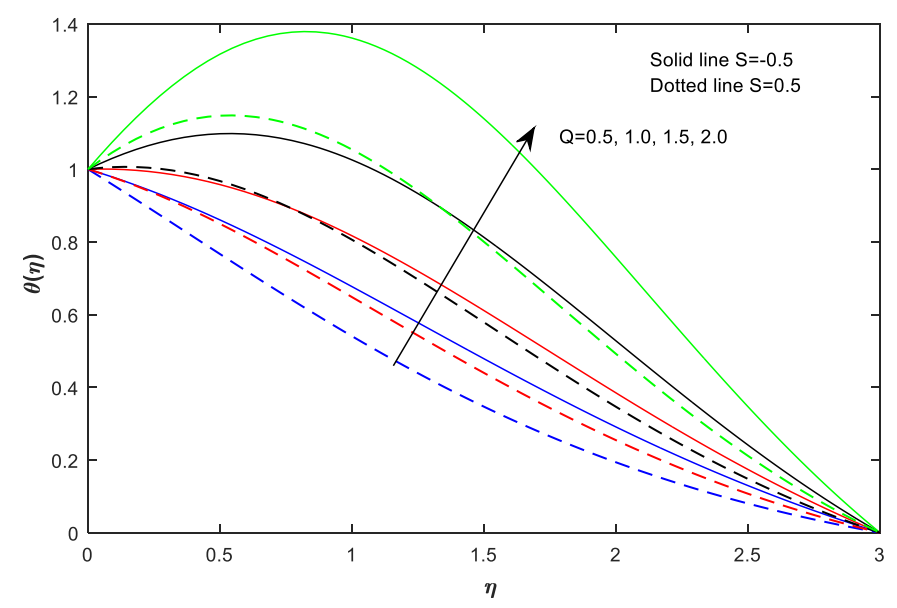

Figure 20 Temperature profiles for different values ofheat source parameter(Q)

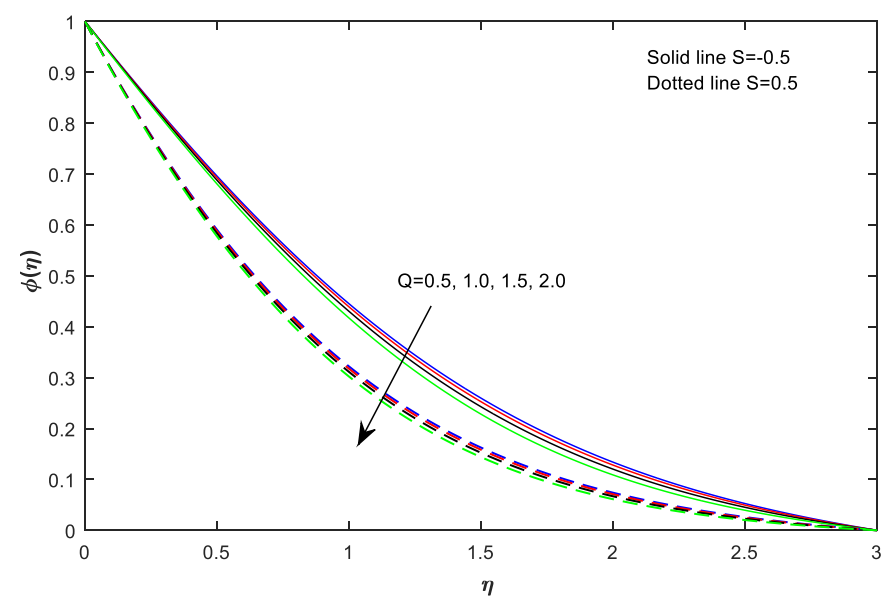

Figure 21 Concentration profiles for different values ofheat source parameter(Q)

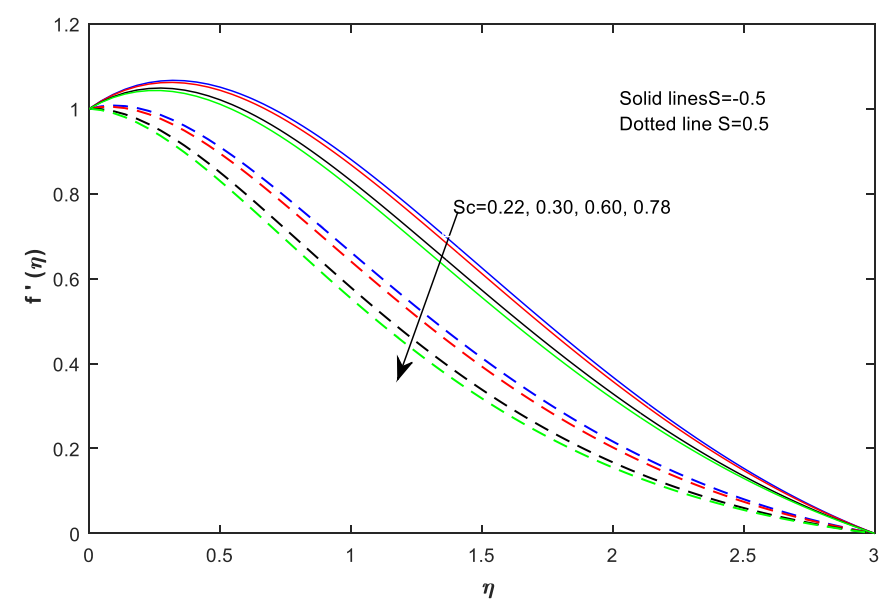

Figure 22 Velocity profiles for different values of Schmidt number ( $\mathrm{Sc}$ ) 
Radiation and Chemical Reaction Effects on MHD Casson Fluid Flow of a Porous Medium with Suction/Injection

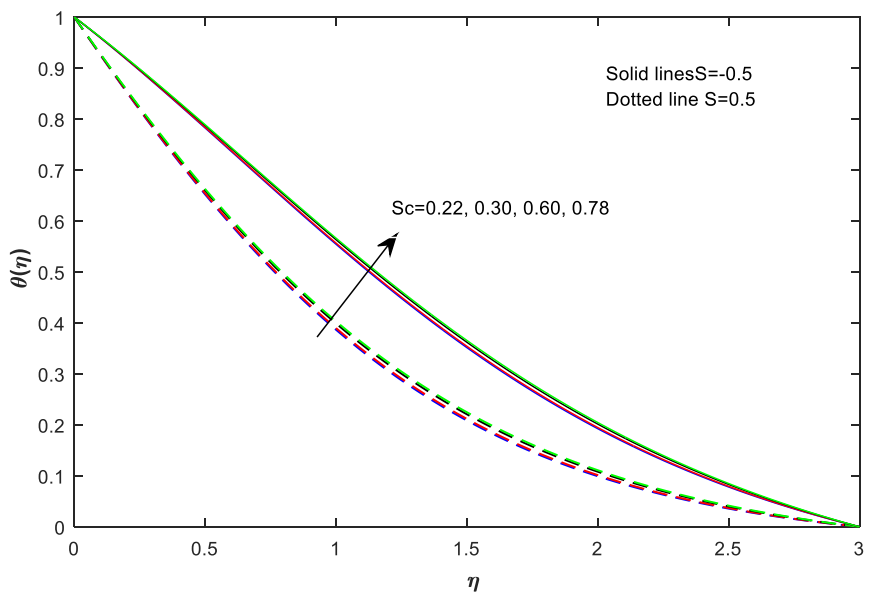

Figure 23 Temperature profiles for different values of Schmidt number (Sc)

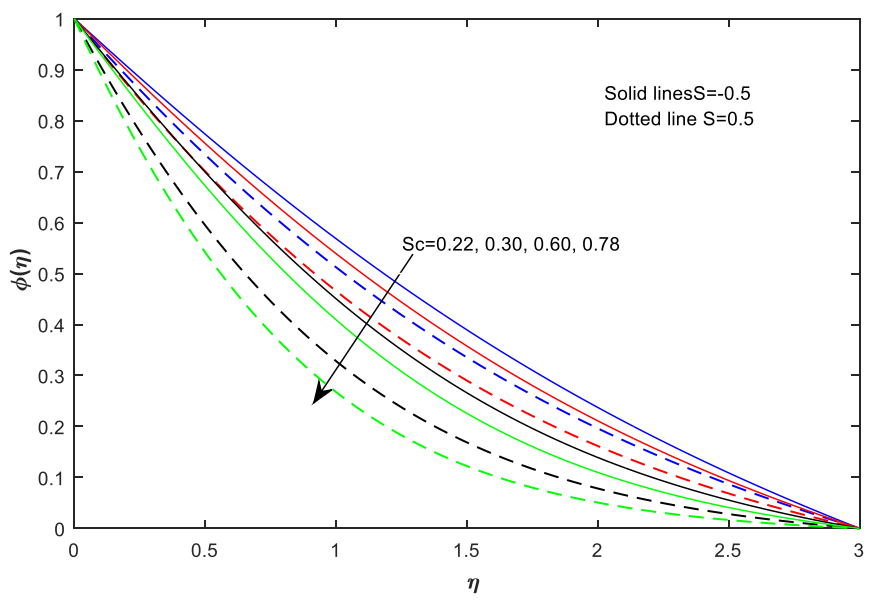

Figure 24 Concentration profiles for different values of Schmidt number (Sc)

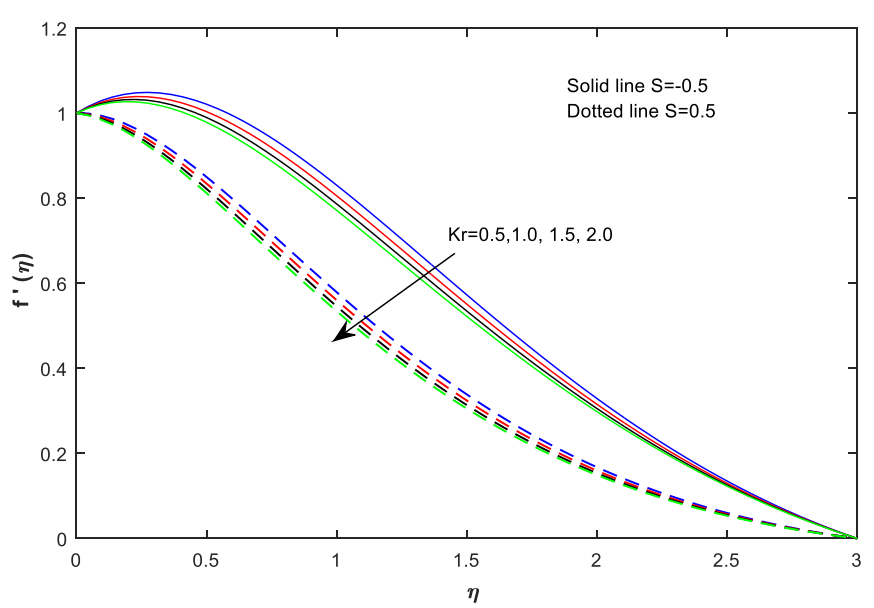

Figure 25 Velocity profiles for different values of chemical reaction $(\mathrm{Kr})$ 


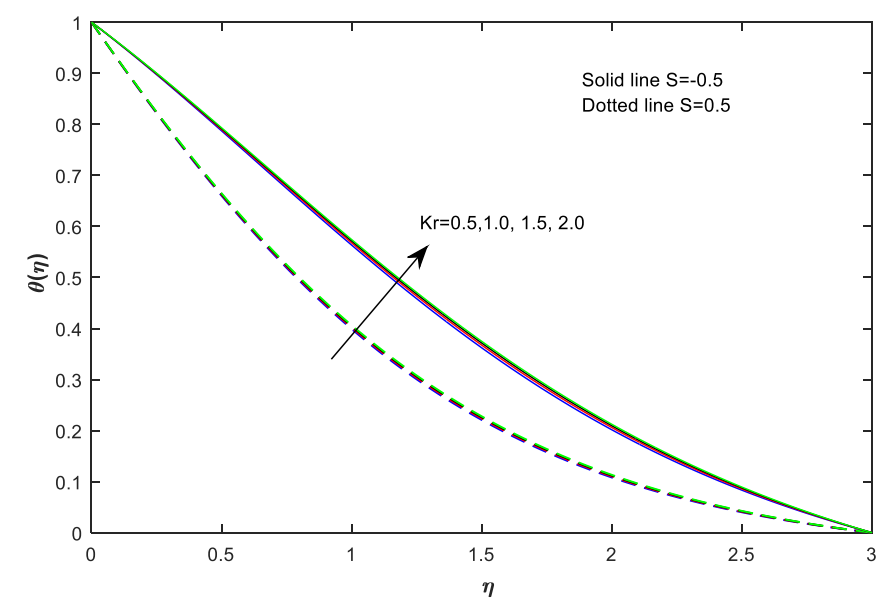

Figure 26 Temperature profiles for different values of chemical reaction $(\mathrm{Kr})$

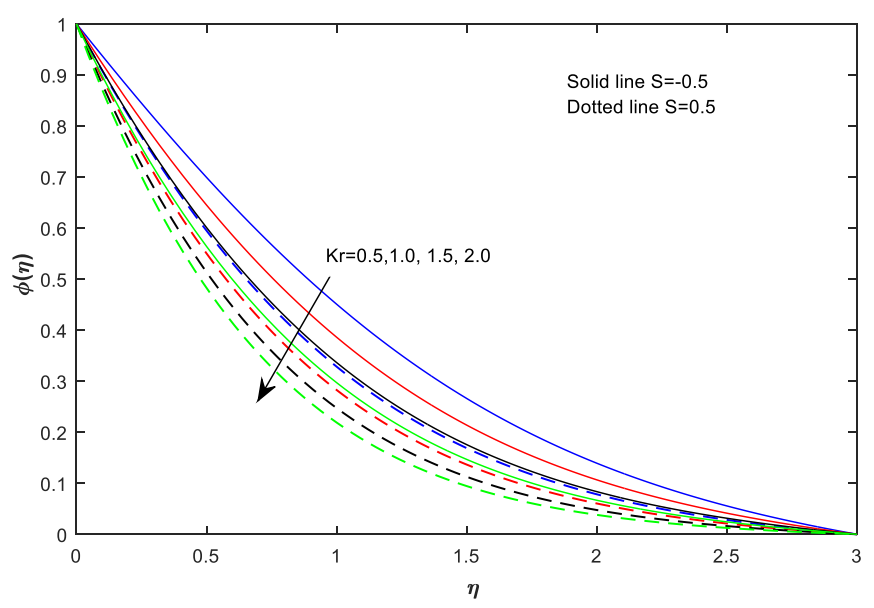

Figure 27 Concentration profiles for different values of chemical reaction $(\mathrm{Kr})$

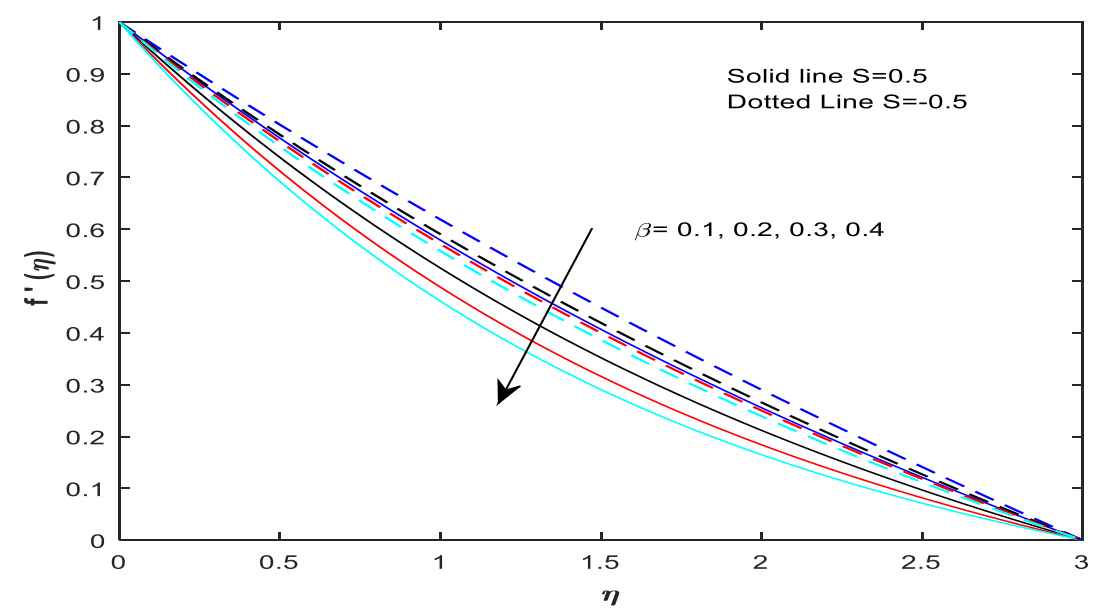

Figure 28 Velocity profiles for different values Casson fluid parameter $(\beta)$. 


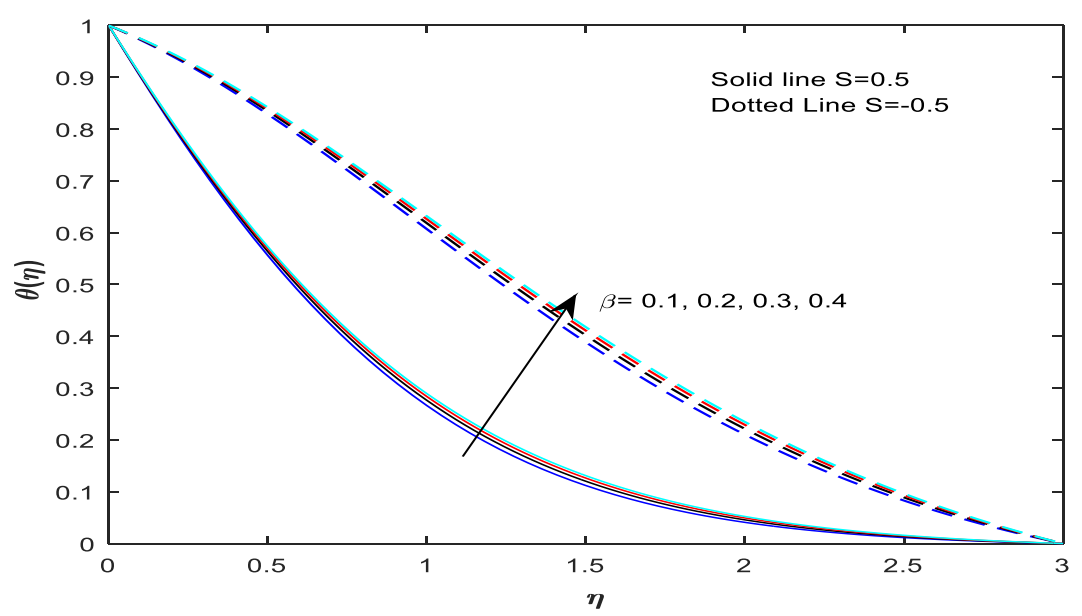

Figure 29 Temperature profiles for different values Casson fluid parameter $(\beta)$.

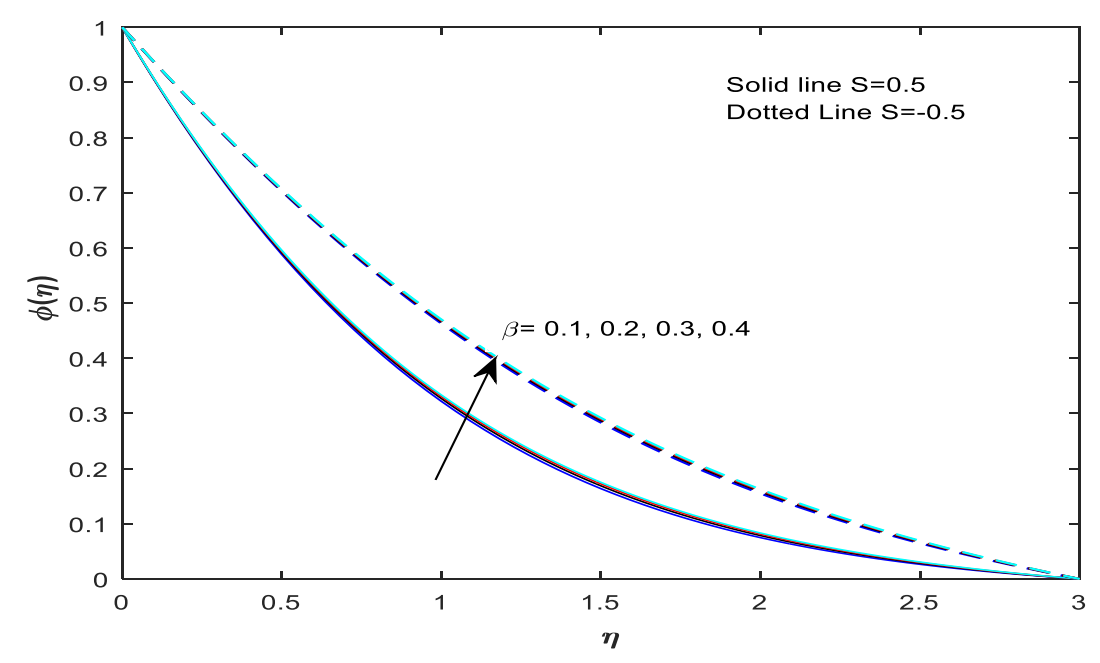

Figure 30 Concentration profiles for different values Casson fluid parameter ( $\beta$ ).

\section{CONCLUSIONS}

The above research discussion proposed the influence of heat source, mass transfer and radiation on steady 2D MHD flow of Casson fluid over a permeable stretching sheet through porous medium in the presence of suction/injection using Applied Numerical Analysis. The conclusions of the above discourse are:

- Velocity increases when Gr, Gm, R and Q increase.

- Velocity decreases when M, K, Pr, Sc and Kr increase

- $\mathrm{M}, \mathrm{K}, \mathrm{R}, \mathrm{Q}, \mathrm{Sc}$ and $\mathrm{Kr}$ increase with increase in temperature.

- $\mathrm{Gr}, \mathrm{Gm}$ and Pr increase with decrease in temperature.

- Concentration increases when M, K and Pr increase.

- Concentration decreases when Gr, Gm, Q, Sc and $\mathrm{Kr}$ decrease. 


\section{REFERENCES}

[1] A.V. Kuznetsov, D.A. Nield, Natural convection boundary layer flow of a nanofluid past a vertical plate, Int. J. Therm. Sci. 40 (2001) 115-124.

[2] Nabil T.M. Eldabe, Galal M. Moatimid, Hoda S.M. Ali, Magnetohydrodynamic flow of non-Newtonian visco-elastic fluid through a porous medium near an accelerated plate, Can. J. Phys. 81 (2003) 1249-1269.

[3] Nabil T.M. Eldabe, S.N. Sallam, Non-Darcy couette flow through a porous medium of magnetohydrodynamic visco-elastic fluid with heat and mass transfer, Can. J. Phys. 83 (2005) 1241-1263.

[4] M. Hameed, S. Nadeem, Unsteady MHD flow of a non-Newtonian fluid on a porous plate, J. Math. Anal. Appl. 325 (2007) 724-733.

[5] V. Rajesh, MHD effects on free convection and mass transform flow through a porous medium with variable temperature, Int. J. Appl. Math. Mech. 6 (2010) 1-16.

[6] S. Sengupta, Thermal diffusion effect of free convection mass transfer flow past a uniformly accelerated porous plate with heat sink, Int. J. Math. Archive 2 (2011) 1266-1273.

[7] Bhattacharya, K. (2011), "Effects of heat source/sink on MHD flow and heat transfer over a shrinking sheet with mass suction", Chemical Engineering Research Bulletin, Vol. 15 No. 1, pp. 12-17.

[8] M. Turkyilmazoglu, I. Pop, Soret and heat source effects on the unsteady radiative MHD free convection flow from an impulsively started infinite vertical plate, Int. J. Heat Mass Transf. 55 (2012) 7635-7644.

[9] M. Narahari, An exact solution of unsteady MHD free convection flow of a radiating gas past an infinite inclined isothermal plate, Appl. Mech. Mater. 110-116 (2012) 2228-2233.

[10] S. Nadeem, R.L. Haq, N.S. Akbar, Z.H. Khan, MHD three-dimensional Casson fluid flow past a porous linearly stretching sheet, Alex. Eng. J. 52 (2013) 577-582.

[11] R.L. Haq, S. Nadeem, Z.H. Khan, T.G. Okedayo, Convective heat transfer and MHD effects on Casson nanofluid flow over a shrinking sheet, Cent. Eur. J. Phys. 12 (12) (2014) 862-871.

[12] P.K. Kameswarani, S. Shaw, P. Sibanda, Dual solutions of Casson fluid flow over a stretching or shrinking sheet, Sadhana 39 (6) (2014) 1573-1583.

[13] Babu, P.R., Rao, J.A. and Sheri, S. (2014), "Radiation effect on MHD heat and mass transfer flow over a shrinking sheet with mass suction", Journal of Applied Fluid Mechanics, Vol. 7 No. 4, pp. 641-650.

[14] C.K. Kirubhashankar, S. Ganesh, A. Mohamed Ismail, Casson fluid flow and heat transfer over an unsteady porous stretching surface, Appl. Math. Sci. 9 (7) (2015) 345-351.

[15] Mabood, F., Khan, W.A. and Ismail, A.I.M. (2015), "MHD boundary layer flow and heat transfer of nanofluids over a nonlinear stretching sheet", Journal of Magnetism and Magnetic Materials, Vol. 374, pp. 569-576, doi: org/10.1016/j.jmmm.2014.09.013.

[16] Hari R. Kataria, Harshad R. Patel: Radiation and chemical reaction effects on MHD Casson fluid flow past an oscillating vertical plate embedded in porous medium,Alexandria Engineering Journal, Volume 55, Issue 1, 2016, pp. 583-595

[17] C.S.K. Raju, N. Sandeep, V. Sugunamma, M. JayachandraBabu, J.V. Ramana Reddy, Heat and mass transfer in magnetohydrodynamic Casson fluid over an exponentially permeable stretching surface, Engineering Science and Technology, an International Journal 19 (2016) 45-52

[18] Mabood, F. and Ibrahim, S.M. (2016), "Effects of Soret and non-uniform heat source on MHD non-Darcian convective flow over a stretching sheet in a dissipative micropolar fluid with radiation", Journal of Applied Fluid Mechanics, Vol. 9 No. 5, pp. 2503-2513.

[19] Yasin, M.H.M., Ishak, A. and Pop, I. (2016), "MHD heat and mass transfer flow over a permeablestretching/shrinking sheet with radiation effect", Journal of Magnetism and 
Magnetic Materials, Vol. 407, pp. 235-240, available at: https://doi.org/10.1016/j.jmmm.2016.01.087

[20] Bhatti, M.M. and Lu, D.Q. (2017), "Head-on collision between two hydroelastic solitary waves in shallow water", Qualitative Theory of Dynamical Systems, 17(1), pp. 1-20.

[21] HariR.Kataria, Harshad R. Patel, Heat and mass transfer in magnetohydrodynamic (MHD) Casson fluid flow past over an oscillating vertical plate embedded in porous medium with ramped wall temperature, Propulsion and Power Research, 7(3), 2018, Pages 257-267

[22] K. Suneetha, S.M. Ibrahim, G.V. Ramana Reddy, (2018) "Radiation and heat source effects onMHD flow over a permeable stretching sheet through porous stratum with chemical reaction",Multidiscipline Modeling in Materials and Structures, https://doi.org/10.1108/MMMS-12-2017-0159

[23] Ramana Reddy G. V. and Y. Hari Krishna, MHD free convective flow of Casson fluid past over an oscillating vertical porous plate, International Journal of Mathematical Archive9(5), 119-126, 2018.

[24] Reddy G.V.R. and Y.Hari Krishna: 'Soret And Dufour Effects On MHD Micropolar Fluid Flow Over A Linearly Stretching Sheet, Through A Non -Darcy Porous Medium', Int. J. of Applied Mechanics and Engineering), 23(2),485-502, 2018.

[25] Sathies Kumar P. and K. Gangadhar : Effect of chemical reaction on slip flow of MHD Casson fluid over a stretching sheet with heat and mass transfer, Advances in Applied Science Research, 2015, 6(8):205-223

[26] Vijaya N, Y Hari Krishna, K Kalyani, GVR Reddy ,Soret And Radiation Effects On An Unsteady Flow Of A Casson Fluid Through Porous Vertical Channel With Expansion And Contraction, - Frontiers in Heat and Mass Transfer (FHMT), 11,1-11, 2018.

[27] K. Bhattacharyya, T. Hayat, and A. Alsaedi, "Exact solution for boundary layer flow of Casson fluid over a permeable stretching/shrinking sheet," Zeitschrift für Angewandte Mathematik und Mechanik, 2013.

[28] M. Nakamura and T. Sawada, "Numerical study on the flow of a non-Newtonian fluid through an axisymmetric stenosis," Journal of Biomechanical Engineering, vol. 110, no. 2, pp. 137-143, 1988.

[29] Pudhari Srilatha and M N Raja Shekar, Radiation Effect on Natural Convective MHD Flow through a Porous Medium with Double Diffusion in the Presence of Chemical Reaction, International Journal of Civil Engineering and Technology, 9(5), 2018, pp. 441-449

[30] N. Mahesh Babu, R.L.V. Renuka Devi, M. Eswara Rao and M. Krishna Murthy, Hydromagnetic Flow of Casson Fluid through a Vertical Deformable Porous Stratum with Viscous Dissipation and Chemical Reaction, International Journal of Mechanical Engineering and Technology, 9(10), 2018, pp. 846-854

[31] K.V. Chandra Sekhar and V. Manjula, MHD Slip Flow of Casson Fluid Over an Exponentially Stretching Inclined Permeable Sheet with Soret-Dufour Effects. International Journal of Civil Engineering and Technology, 9(3), 2018, pp. 400-417.

[32] P.D. Selvi, S. Sreenadh and E. Kesava Reddy, Pulsatile Flow of a Casson Fluid between Permeable Beds, International Journal of Mechanical Engineering and Technology, 9(8), 2018, pp. 589-600. 